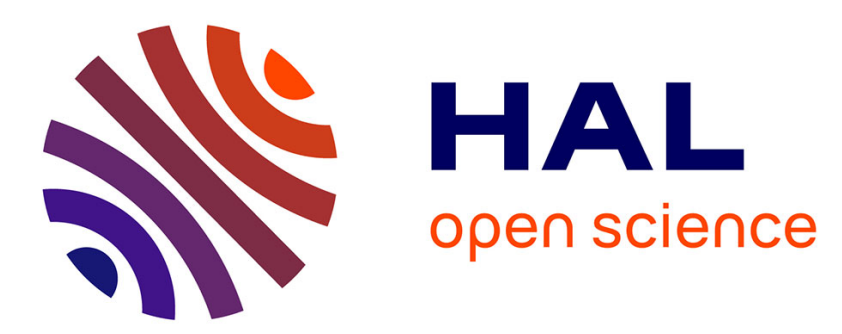

\title{
Abnormal connexion of the coronary sinus to the left atrium
}

\author{
Jean Nicolas Dacher, P. Michelin, S. Bejar, B. Dubourg
}

\section{To cite this version:}

Jean Nicolas Dacher, P. Michelin, S. Bejar, B. Dubourg. Abnormal connexion of the coronary sinus to the left atrium. Diagnostic and Interventional Imaging, 2018, 99 (9), pp.581-583. 10.1016/j.diii.2018.05.004 . inserm-02457276

\section{HAL Id: inserm-02457276 https://www.hal.inserm.fr/inserm-02457276}

Submitted on 27 Jan 2020

HAL is a multi-disciplinary open access archive for the deposit and dissemination of scientific research documents, whether they are published or not. The documents may come from teaching and research institutions in France or abroad, or from public or private research centers.
L'archive ouverte pluridisciplinaire HAL, est destinée au dépôt et à la diffusion de documents scientifiques de niveau recherche, publiés ou non, émanant des établissements d'enseignement et de recherche français ou étrangers, des laboratoires publics ou privés. 


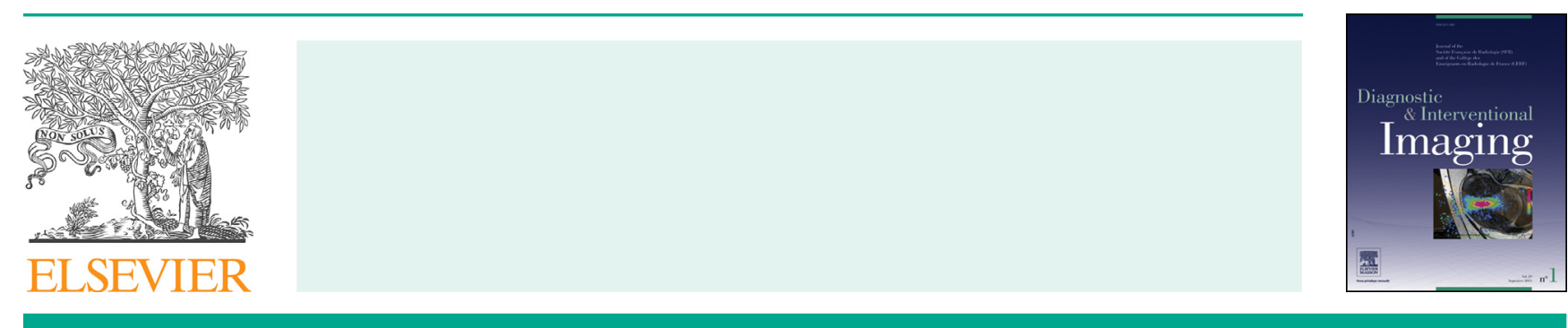

\section{LETTER}

\section{Abnormal connexion of the coronary sinus to the left atrium}

\section{Dear Editor,}

Coronary sinus (CS) is the main venous collector of the heart. In normal configuration, it drains into the right atrium via the Thebesian valve. Among the various malformations of CS, abnormal connexion to the left atrium has been rarely recognized and described [1-3].

A 62-year-old woman received transcatheter aortic valve replacement (TAVR) for aortic valve disease as she had contra-indication to conventional surgery. The procedure was uncomplicated and the patient was referred to ECGgated computed tomography (CT) examination 2 years later because an increased trans-aortic gradient had been identified on tranthoracic echocardiography (TTE). Minimal leaflet thrombosis was diagnosed that would require anticoagulant therapy and further TTE and CT follow-up. CT revealed varicosities located on the anterior aspect of the heart and great vessels (Fig. 1). Those dilated veins were connected to the great cardiac vein then to the CS. Coronary artery disease was disclosed but there was no dilated coronary artery segment and no argument for arterial-venous fistula. The explanation for this dilated venous network came from the analysis of the CS termination. Neither ostium nor
Thebesian valve could be found in the right atrium. The distal CS presented a siphon-shaped path and connected via a large opening to the left atrium. Its calibre $(<1 \mathrm{~cm})$ was within the normal range. Unroofed CS could be evoked but this diagnosis, an equivalent of atrial septal defect, was incorrect as there was no connexion at all to the right atrium and no dilatation of right heart cavities. Hence, the final diagnosis was abnormal connexion of the CS to the left atrium. The left atrial pressure system could explain the stagnation of venous blood in the CS and its tributaries. As the abnormality did not come with hemodynamic consequences, surgery was not considered. No other significant malformation was present; a tiny left superior vena cava was disclosed among the many tributaries of CS, probably serving as an egress to the coronary venous blood flow [4]. Retrospective analysis of the pre-TAVR CT was performed. It confirmed that the malformation had been overlooked pre operatively and that no anatomic change occurred with the endovascular procedure.

Although cardiac CT is widely accepted for the assessment of coronary artery disease [5], it is less renowned for the evaluation of the coronary veins and CS. However, analysis of the CS should be part of the analysis of any cardiac CT as its cannulation is frequently required to place electrophysiology devices in the context of ventricular pacing or mapping and ablation of arrhythmias. 

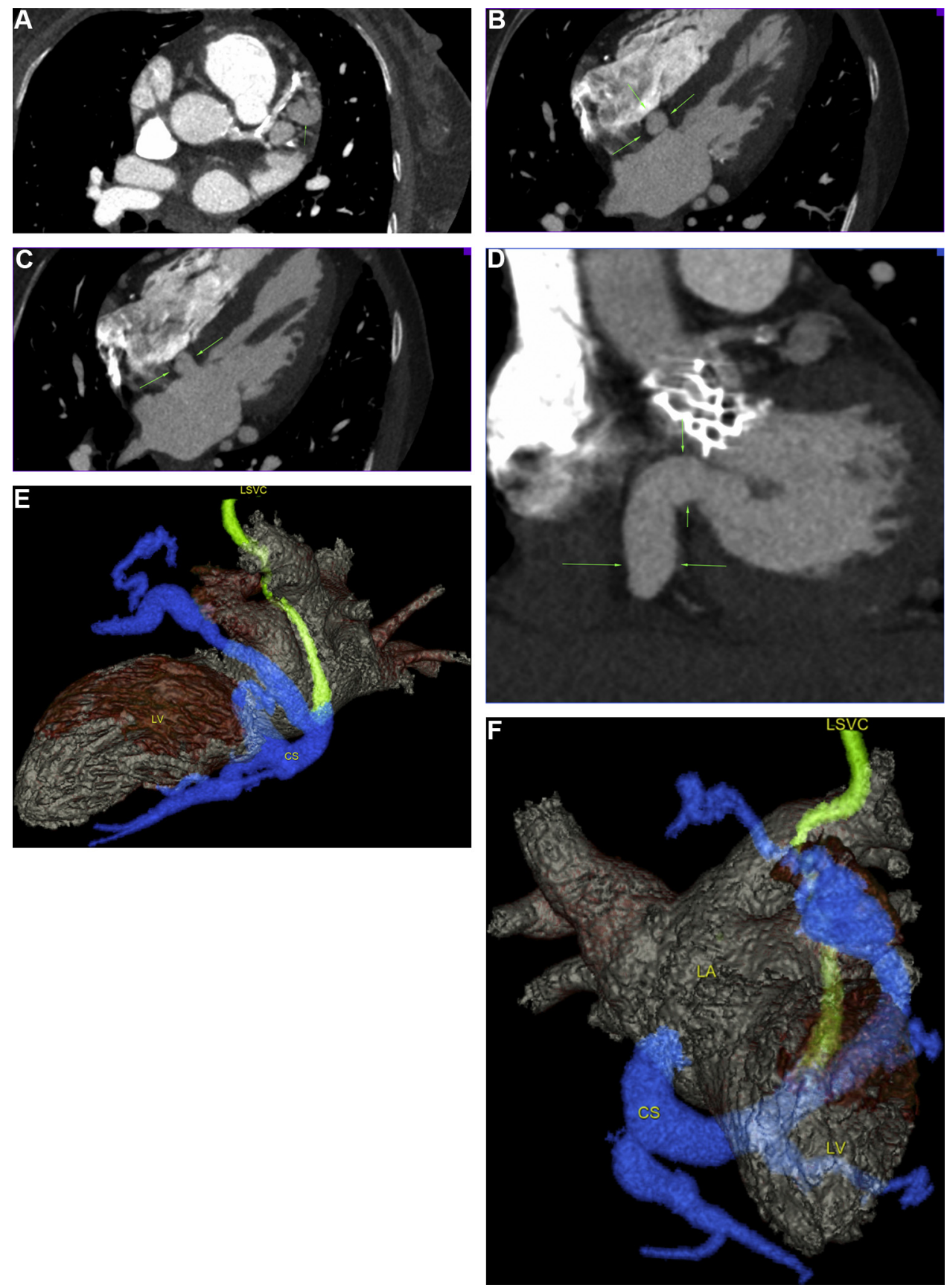

Figure 1. A 62-year-old woman with abnormal connexion of the coronary sinus to the left atrium. A. CT image in the transverse plane shows varicosities on the superior aspect of the left ventricle (arrow). Note coronary artery disease and normal calibre of coronaries (left main and left anterior descending). B, CT image in the transverse plane shows the distal coronary sinus (arrows). Note the absence of communication with right atrium and dilated veins in the left atrio-ventricular groove. C, CT image just above B shows the wide opening of the coronary sinus (arrows) into the left atrium. D, Coronal view of the distal coronary sinus (arrows) shows its wide opening in the left atrium, caudal to the aortic valve prosthesis. E, F. Volume rendering obtained from CT. Left lateral (E) and anterior views (F) show the great cardiac vein and coronary sinus (CS, blue) as well as the tiny left superior vena cava (LSVC, green). LV indicates left ventricle. LA indicates left atrium.

\section{Disclosure of interest}

The authors declare that they have no competing interest.

\section{References}

[1] Ozturk E, Kafadar C, Dogan M, Uz O. Anomalous cardiac venous connection to the left atrium associated with coronary sinus atresia. Korean J Radiol 2014;15:879-81.
[2] Capuñay C, Carrascosa P, Deviggiano A, López EM. Anomalous coronary sinus drainage into the left atrium. J Cardiovasc Comput Tomogr 2009;3:112-3.

[3] Chou MC, Wu MT, Chen CH, Lee MH, Tzeng WS. Multidetector CT findings of a congenital coronary sinus anomaly: a report of two cases. Korean J Radiol 2008;9Suppl:S1-6.

[4] Demeyere M, Delacour D, Bouchart F, Michelin P, Bauer F, Dubourg B, et al. Persistent left superior vena cava: an unusual 
cause of curable pulmonary hypertension. Diagn Interv Imaging 2018;99:47-8.

[5] Sorensen C, Dabadie A, Pico H, Gach P, Dehaene A, Gaubert JY, et al. Cardiac imaging: from fetus to adult. Diagn Interv Imaging 2016;97:503-4.

J.-N. Dacher ${ }^{a, b, *}$, P. Michelin ${ }^{a}$, S. Bejar ${ }^{a}$, B. Dubourg ${ }^{a, b}$ a Department of Radiology, Cardiac Imaging Unit, University Hospital of Rouen, 1, rue de Germont, 76031 Rouen, France

b Inserm U1096, UFR médecine pharmacie, 22, boulevard Gambetta, 76183 Rouen, France
* Corresponding author. Unité d'imagerie cardiaque, Service de radiologie, CHU Rouen, 1, rue de Germont, 76031 Rouen cedex, France.

E-mail address: jean-nicolas.dacher@chu-rouen.fr

(J.-N. Dacher)

https://doi.org/10.1016/j.diii.2018.05.004

2211-5684/ ( 2018 Published by Elsevier Masson SAS on behalf of the Société française de radiologie. 